\title{
Development of biosurfactant-based graphene quantum dot conjugate as a novel and fluorescent theranostic tool for cancer
}

This article was published in the following Dove Medical Press journal: International Journal of Nanomedicine

\author{
Smriti Bansal' \\ Joga Singh ${ }^{2}$ \\ Uma Kumari ${ }^{3}$ \\ Indu Pal Kaur ${ }^{2}$ \\ Ravi Pratap Barnwal ${ }^{4}$ \\ Ravinder Kumar ${ }^{3}$ \\ Suman Singh ${ }^{5}$ \\ Gurpal Singh ${ }^{2}$ \\ Mary Chatterjee' \\ 'Biotechnology Engineering, \\ University Institute of Engineering \\ \& Technology, Panjab University, \\ Chandigarh, India; ${ }^{2}$ Department of \\ Pharmaceutical Sciences, University \\ Institute of Pharmaceutical Sciences, \\ Panjab University, Chandigarh, \\ India; ${ }^{3}$ Department of Zoology, \\ Panjab University, Chandigarh, \\ India; ${ }^{4}$ Department of Biophysics, \\ Panjab University, Chandigarh, India; \\ ${ }^{5}$ Department of Agronomics, Central \\ Scientific Instruments Organisation, \\ Chandigarh, India
}

Correspondence: Mary Chatterjee Biotechnology Engineering, University Institute of Engineering and Technology, Sector- 25, Panjab University, Chandigarh, |600|4, India

Emailmaryc@pu.ac.in

Gurpal Singh

Department of Pharmaceutical Sciences, University Institute of Pharmaceutical Sciences, Panjab University, Chandigarh, India

Email gurpal79@pu.ac.in
Background: Biosurfactants are amphipathic molecules of microbial origin that reduce surface and interfacial tension at gas-liquid-solid interfaces. Earlier, the biosurfactant was isolated and characterized in our laboratory from Candida parapsilosis. The property of the biosurfactant is further explored in this study by using quantum dots (QDs) as nanocarrier.

Materials and methods: Graphene quantum dots (GQDs) were synthesized by bottom-up approach through pyrolysis of citric acid. GQDs were conjugated with both biosurfactant and folic acid (FA) using carbodiimide chemistry. The prepared GQD bioconjugate was studied for diagnostic and therapeutic effects against cancer cells.

Results and discussion: Photoluminescence quantum yield (QY) of plain GQDs was measured as $12.8 \%$. QY for biosurfactant conjugated GQDs and FA-biosurfactant conjugated GQDs was measured as $10.4 \%$ and $9.02 \%$, respectively, and it was sufficient for targeting cancer cells. MTT assay showed that more than $90 \%$ of cells remained viable at concentration of $1 \mathrm{mg} / \mathrm{mL}$, hence GQDs seemed to be non-toxic to cells. Biosurfactant conjugated GQDs caused 50\% reduction in cellular viability within 24 hours. FA conjugation further increased the specificity of bioconjugated GQDs toward tumor cells, which is clearly evident from the drug internalization studies using confocal laser scanning microscopy. A higher amount of drug uptake was observed when bioconjugated GQDs were decorated with FA.

Conclusion: The ability of GQD bioconjugate could be used as a theranostic tool for cancer. It is foreseen that in near future cancer can be detected and/or treated at an early stage by utilizing biosurfactant conjugated GQDs. Therefore, the proposed study would provide a stepping stone to improve the life of cancer patients.

Keywords: bioconjugation, nanomedicine, nanocarrier, cancer therapy, folic acid receptor, graphene quantum dots

\section{Introduction}

The application of quantum dots (QDs) has increased with the advent of nanotechnology. QDs are integrated with various biomolecules for specific targeting and purposes in the field of biological and medical sciences. ${ }^{1}$ This is because of their small size, narrow emission spectra over broad excitation spectra, high fluorescent quantum yields, and resistance to photo-bleaching. ${ }^{2,3}$ Earlier, metallic QDs such as CdS, CdSe, and CdTe were the most investigated QDs due to their excellent optical and electrochemical properties. ${ }^{4}$ However, cytotoxicity caused by metallic QDs hampers their practical applications in biology. Therefore, demand for biocompatible QDs has led to the discovery of carbon-based nanomaterials. ${ }^{3-5}$ 
Carbon nanodots (CNDs) are one of the popular nanomolecules in scientific communities. ${ }^{67}$ Fluorescent graphene quantum dots (GQDs), a class of CNDs, with tunable emissions are considered to be the next-generation nanomaterials., ${ }^{3,7-9}$ Their properties include stable photoluminescence (PL), high solvent dispersibility, low cytotoxicity, and excellent biocompatibility, ${ }^{7,10}$ which make GQDs an attractive tool for diagnosis and therapy. ${ }^{5,7,10}$

Graphene is an allotrope of carbon, and consists of thin sheet of carbon atoms arranged in a hexagonal lattice., ${ }^{78}$ Briefly, GQDs can be fabricated using top-down and bottomup approaches..$^{6-8,11,12}$ Pyrolysis of citric acid is one of the well-established method for the preparation of GQDs. It is a convenient and economical method in terms of precursors used and method followed for its synthesis. ${ }^{13-15}$ GQDs are formed by varying the carbonization degree of citric acid. ${ }^{6}, 13$ Lately, the interest in bioconjugated GQDs has been increasing at an outstanding rate. ${ }^{5}$ Biomolecules conjugated with GQDs can be used as theranostic tool against deadly diseases like cancer. These nanoconjugates exhibit targetability and have imaging properties enabling them to be used in downstream screening purposes. ${ }^{1}$ Very recently, by utilizing unique physicochemical properties of GQDs, Ding et al had developed a novel type of theranostic agent by loading anticancer drug doxorubicin (DOX) to GQD's surface and conjugating Cy5.5 (Cy) dye to GQD through a cathepsin D-responsive (P) peptide. Authors reported superior therapeutic performance of this type of agents along with functioning as probes for tracking the delivery and release of anticancer drug as well as drug-induced cancer cell apoptosis. ${ }^{16}$ Recent review by Iannazzo et al discussed the application of GQDs as nanoplatforms for anticancer therapy. ${ }^{17}$ Authors covered the methodology for synthesis and functionalization procedures of this agent, and discussed how it can affect their biocompatibility and physicochemical features. Wang et al showed efficient delivery of DOX to the nucleus through DOX/GQD conjugates. Authors also added that conjugates could markedly enhance DNA cleavage activity of DOX. DOX/GQD conjugates improved cytotoxicity of DOX dramatically. Furthermore, the DOX/ GQD conjugates could also increase the nuclear uptake and cytotoxicity of DOX toward drug-resistant cancer cells, indicating that the conjugates were capable of increasing chemotherapeutic efficacy of anticancer drugs. ${ }^{18}$

Biosurfactants are amphipathic molecules of microbial and plant origin. Owing to their structural diversity, biodegradability, and non-toxicity, they are used in biomedical field. ${ }^{19}$ Biosurfactants are proposed as suitable drug candidates against many diseases including cancer. ${ }^{20,21}$ Literature showed cytotoxicity of these molecules against different cancer cell lines. Huang et al reported that surfactin-based nanocarrier might be a promising platform to reverse multidrug resistance in cancer chemotherapy. ${ }^{22}$ In cancerous cells, various receptors like folic acid (FA), arginine-glycineaspartic acid, hyaluronic acid, and antibodies are overexpressed. ${ }^{23}$ On the contrary, expression of these receptors is significantly low in normal cells. ${ }^{23,24}$ FA can be used to increase internalization of nanoconjugates by targeting cells via receptor-mediated endocytosis. ${ }^{23,25,26}$ Therefore, FA receptors would be a targeting marker for selective imaging and therapy of cancer. ${ }^{27}$

Chemotherapeutic drugs/GQD-based nanosystem is developed to enhance efficiency of drug to kill cancerous cells. ${ }^{28}$ It is observed that this nanosystem can increase the chemotherapeutic efficacy of anticancer drugs. ${ }^{29}$ Until now, most of the studies related to the development of theranostic tool for cancer using GQDs was based on the use of standard chemotherapeutic drugs. Our present study focuses on the use of a biosurfactant which is supposed to be less toxic, having minimum side effects and more biodegradability compared to standard chemotherapeutic drugs used for cancer therapy. This biosurfactant was isolated from Candida parapsilosis in our laboratory. This study was directed toward the synthesis and characterization of GQDs through pyrolysis of citric acid and its conjugation with biosurfactant. There have been no previous reports regarding conjugation of biosurfactant with GQDs for the development of theranostic tool against cancer. Hence, this study is an initial step to explore a novel bioconjugate for the diagnosis and therapy of cancer.

\section{Materials and methods Chemicals and materials}

Dimethyl sulfoxide (DMSO), DAPI, $N$-(3 dimethylaminopropyl)- $N$-ethylcarbodiimidehydrochloride (EDC), and $\mathrm{N}$-hydroxysuccinimide (NHS) were purchased from SigmaAldrich Co. (St Louis, MO, USA). Sodium hydroxide pellets, FA, and citric acid monohydrate were purchased from SRL, New Delhi, India. RPMI-1640, PBS, FBS, trypsin, penicillin, streptomycin, and MTT reagent were purchased from Himedia (Mumbai, India).

\section{Microorganism and culture conditions}

The fungal culture of $C$. parapsilosis was isolated from environmental source in our laboratory. Culture was grown in potato dextrose broth media at $37^{\circ} \mathrm{C}$ for 48 hours. ${ }^{30}$ 


\section{Production of biosurfactant}

Biosurfactant was isolated from C. parapsilosis using acid precipitation approach. Details of the methodology for extraction of biosurfactant have been reported previously. ${ }^{30}$

\section{Synthesis of GQDs}

GQDs were prepared by bottom-up approach with minor modifications of previously reported methodologies..$^{14,15,31}$ Briefly, $2 \mathrm{~g}$ of citric acid was heated upto $160^{\circ} \mathrm{C}$ for about 15 minutes under continuous mixing, until the color of citric acid changed to orange. Further, $100 \mathrm{~mL}$ of $1.5 \mathrm{M} \mathrm{NaOH}$ solution ${ }^{14,15,31}$ was added dropwise into pyrolyzed citric acid under vigorous stirring. The $\mathrm{pH}$ of pale yellow GQD solution was adjusted to 7.0 with $1 \mathrm{~N} \mathrm{HCl}$ solution. The product was subsequently freeze-dried and stored in vials for further use.

\section{Preparation of GQDs-biosurfactant conjugates}

GQDs were activated by mixing $25 \mathrm{~mL}$ of GQDs $(85 \mathrm{mg} / \mathrm{mL}$ in PBS, pH 7.4) solution with EDC (2 mg) and NHS (3 mg) at room temperature (RT) for 1 hours. EDC and NHS were mixed in the ratio $2: 3$. Then, $300 \mu \mathrm{L}$ of biosurfactant ( $1 \mathrm{mg} / \mathrm{mL}$ in PBS, pH 7.4) was conjugated to GQDs through amine-carboxyl coupling reaction for 1 hours at RT with stirring. GQDs-biosurfactant conjugates (biosurfactant-GQDs) were separated from free cross-linkers by centrifugation (6,000 rpm, 5 minutes) and kept at $4^{\circ} \mathrm{C} ., 23$

\section{Preparation of GQDs-biosurfactant-FA conjugate}

For folate conjugation, $3 \mathrm{~mL}$ of biosurfactant conjugated GQDs were mixed with $30 \mu \mathrm{L}$ of FA (1 mM in PBS) and incubated for 1 hour at RT with stirring. Folate decorated GQDs were separated from excess free FA by centrifugation (6,000 rpm for 15 minutes). Finally, purified folate conjugated GQDs (FA-biosurfactant-GQDs) were stored at $4^{\circ} \mathrm{C}$ till further use. ${ }^{1,23,32}$

\section{Characterization}

GQDs and their bioconjugates were characterized by spectrophotometeric techniques such as transmission electron microscopy (TEM), Fourier-transform infrared spectroscopy (FTIR), X-ray diffraction (XRD), and zeta potential. The optical studies were investigated by PL and UV-visible spectroscopy. PL was recorded on F-2500 Fluorescence spectrometer (Hitachi Ltd., Tokyo, Japan). UV/Vis absorption spectra were obtained on Lambda 35 (PerkinElmer Inc., Waltham, MA, USA) spectrometer.
TEM (JEOL, Tokyo, Japan) was employed for analysis of morphology of the prepared samples. Powdered XRD (PANalytical, Almelo, the Netherlands) was performed for analyzing surface characterstics of the particles. Zeta potential was measured for size and charge determination using Malvern Zetasizer. FTIR (Perkin Elmer) demonstrated the chemical nature of novel compounds. Confocal laser scanning microscopy (CLSM) using NIKON C2+ instrument was performed to determine cellular internalization of drugs by cancerous cells.

\section{Cytotoxicity assay}

MCF-7 (human breast cancer) cell line was procured from National Center for Cell Science (NCCS), Pune, India. Cells were grown in a RPMI-1640 medium containing 10\% FBS, $100 \mathrm{U} \cdot \mathrm{mL}^{-1}$ penicillin and streptomycin at $37^{\circ} \mathrm{C}$, and $5 \%$ $\mathrm{CO}_{2}$. The cells were grown in abovementioned conditions for 2-3 days. ${ }^{5}$ The cytotoxicity study was performed using MTT reduction assay. Cells were grown on a 96-well plate at a density of $1 \times 10^{4}$ cells/well. After overnight incubation, GQD solutions (500, 1,000, and $2,000 \mu \mathrm{g} / \mathrm{mL}$ ) were added to respective wells and incubated for 24 and 48 hours in 5\% $\mathrm{CO}_{2}$ at $37^{\circ} \mathrm{C}$. Afterward, $50 \mu \mathrm{L}$ of MTT solution $(1 \mathrm{mg} / \mathrm{mL}$ in PBS) was added in each well and incubated for 4 hours followed by DMSO addition. The absorbance of produced formazon was monitored on ELISA reader at $460 \mathrm{~nm} ., 33$ Moreover, MTT assays for folate decorated bioconjugated GQDs (1,000 $\mu \mathrm{g} / \mathrm{mL}$ of GQDs) were also performed using different dosage concentrations of biosurfactant (2.5 and $5 \mu \mathrm{g} / \mathrm{mL})$.

\section{Cellular uptake studies of GQDs and GQDs bioconjugates}

In cellular uptake studies, MCF-7 cells were seeded on coverslips in six-well plate $\left(1 \times 10^{4}\right.$ cells/well). After 48 hours, $200 \mu \mathrm{L}$ of GQDs and GQDs conjugates were added in respective wells. After incubation for 1, 3, and 6 hours, nuclei of MCF-7 cells were stained using DAPI $(5 \mu \mathrm{g} / \mathrm{mL}) .{ }^{10}$ Cells were washed with PBS twice to remove unattached cells. Glass coverslips were fixed with $4 \%$ formaldehyde for 20 minutes. Imaging studies were recorded in the wavelength regime of $475-575 \mathrm{~nm}$ on CLSM. ${ }^{23,32}$

\section{Statistical analyses}

The values of results were expressed as mean with SD (mean $\pm \mathrm{SD}$ ). Statistical significance was set at $P<0.05$ for all comparisons and was analyzed using Student's $t$-test. 


\section{Results and discussion Synthesis of GQDs}

GQDs were synthesized with slight modification of pyrolysis method proposed by He et al. ${ }^{31}$ It is a direct, one-step aqueous synthesis method involving components $\mathrm{NaOH}, \mathrm{HCl}$, and citric acid as the main precursors. Heating of the citric acid and subsequent addition of $1.5 \mathrm{M} \mathrm{NaOH}$ resulted in the formation of nanocrystals of GQDs. The prepared nanocrystals of GQDs were highly stable and dispersible in water at $\mathrm{pH}$ 7.4. Nanocrystals emitted green fluorescence in the UV range, when excited at $365 \mathrm{~nm}$. Prepared GQDs were dialyzed for 24 hours before further applications. After dialysis, GQDs were stored at $4^{\circ} \mathrm{C}$ until further use. GQDs exhibit a light yellow color under visible light while under UV light, they exhibit a strong fluorescence emission of green color. ${ }^{33,34}$ This could be visualized in Figure 1.

\section{Characterization}

\section{Optical characteristics of GQDs}

The prepared GQDs have shown strong absorbance at $340 \mathrm{~nm}$ under UV light as shown in Figure 2A. ${ }^{35}$ GQDs after conjugation with biosurfactant showed absorption maxima at $338 \mathrm{~nm}$, whereas FA-biosurfactant-GQDs conjugate showed absorption maxima at $362 \mathrm{~nm}$ (Figure 2A). The shift of peak in bioconjugated GQDs might be due to the strong interaction and attachment of biosurfactant and FA with GODs. ${ }^{5}$ Biosurfactant showed UV-vis absorbance at $263 \mathrm{~nm}$ as observed in Figure 2A. ${ }^{36}$

Figure 2B represents the PL spectra of GQDs, when excited at wavelengths ranging from 360 to $370 \mathrm{~nm}$. It was observed that GQDs exhibited a slight excitation-dependent emission spectra. The maximum emission was obtained at $360 \mathrm{~nm}$. This particular wavelength helped us in imaging the cells and tracking GQDs clearly. Figure 2C manifests the PL intensity of GQDs. Upon excitation at $365 \mathrm{~nm}$, GQDs exhibited a prominent emission peak at $486 \mathrm{~nm}$. It showed high QY (12.8\%), due to the layered structure and better crystallinity as it was confirmed by XRD. ${ }^{37}$ This characteristic emission peak of GQDs did not shift after surface functionalization of GQDs with biosurfactant and FA, as shown in Figure 2. However, fluorescence peak intensity was diminished by $24 \%$ upon conjugation of biosurfactant with GQDs. Further, decrease in fluorescence intensity by $15 \%$ was observed upon decoration with FA (10 $\mu \mathrm{M}$ FA) (Figure 2C). Decreased fluorescence intensity of bioconjugated GQDs was attributed to change in the QDs electronic energy. Chemical interactions, or local or electric or stress field occurred on QDs surface during bioconjugation process. ${ }^{1}$ However, biosurfactant itself did not show fluorescence under UV light. This was further demonstrated by PL spectra, where no fluorescence emission peak corresponding to biosurfactant was observed upon excitation at 365 nm. Finally, bioconjugated GQDs exhibited excellent photostability and relatively narrow spectral width under UV illumination. The QY for biosurfactant conjugated GQDs and FA-biosurfactant conjugated GQDs was measured as $10.4 \%$ and $9.02 \%$, respectively. Thus, it provided sufficient spectral resolution for quantitative detection of the fluorescence intensity. ${ }^{37}$

\section{TEM}

The prepared GQDs were found to be round shaped and homogenously dispersed, with depicted size range of $3.5-8 \mathrm{~nm}$. This could be visualized from the TEM images shown in Figure 3. GQDs were nearly identical in shape and well isolated from each other, confirming no aggregation during synthesis of GQDs. The obtained results were in line with the findings of previous studies. ${ }^{31,34,38}$
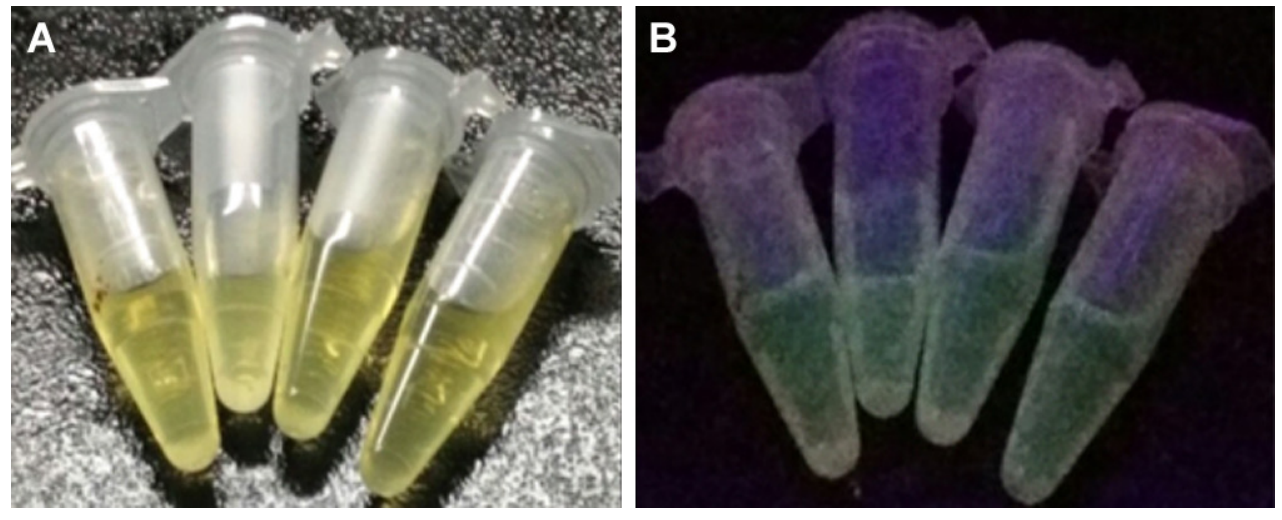

Figure I Optical images of GQDs in aqueous solution: (A) under visible light and (B) under UV irradiation. Abbreviation: GQDs, graphene quantum dots. 

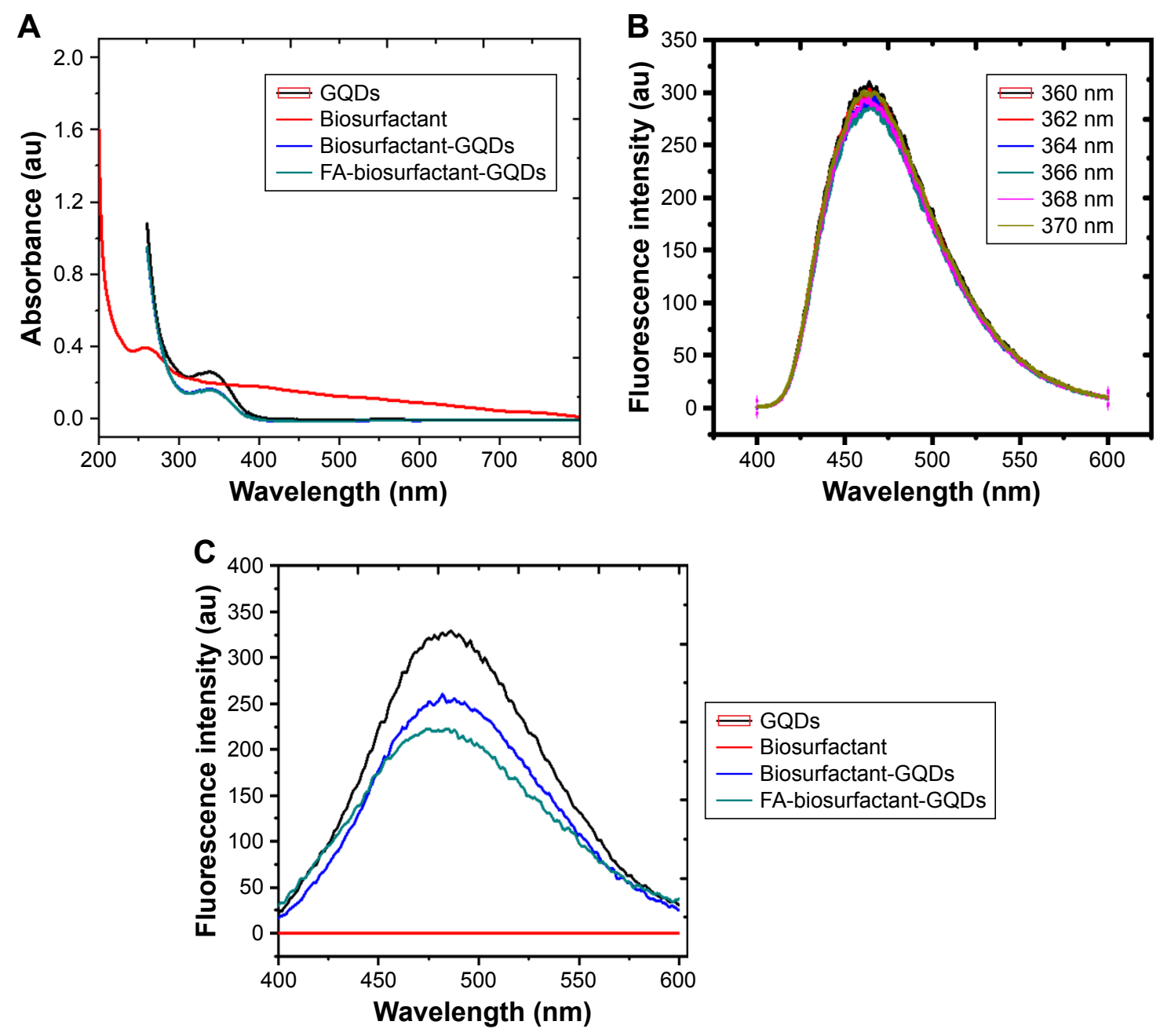

Figure 2 Characterization of biosurfactant, GQDs, biosurfactant-GQDs, and FA-biosurfactant-GQDs conjugates.

Notes: (A) UV-vis absorption spectra. (B) Fluorescence spectra (under different excitation wavelengths ranging from 360 to $370 \mathrm{~nm}$ ). (C) PL decay curves of GQDs and their conjugates under a UV beam of $365 \mathrm{~nm}$.

Abbreviations: FA, folic acid; GQDs, graphene quantum dots; PL, photoluminescence; UV-vis, ultraviolet-visible.

XRD

XRD measurement was carried out to study crystallinity and structure of GQDs. XRD pattern of GQDs showed two peaks near $2 \theta$ value of $31.7^{\circ}$ and $45.8^{\circ}$, which corresponded to (100) and (102) planes of hexagonal carbon, respectively (Figure 4). ${ }^{39}$ The XRD pattern of bioconjugated GQDs (biosurfactant conjugated) showed the peaks near $2 \theta$ value of $14.87^{\circ}, 31.92^{\circ}$, and $41.1^{\circ}$, respectively. These peaks
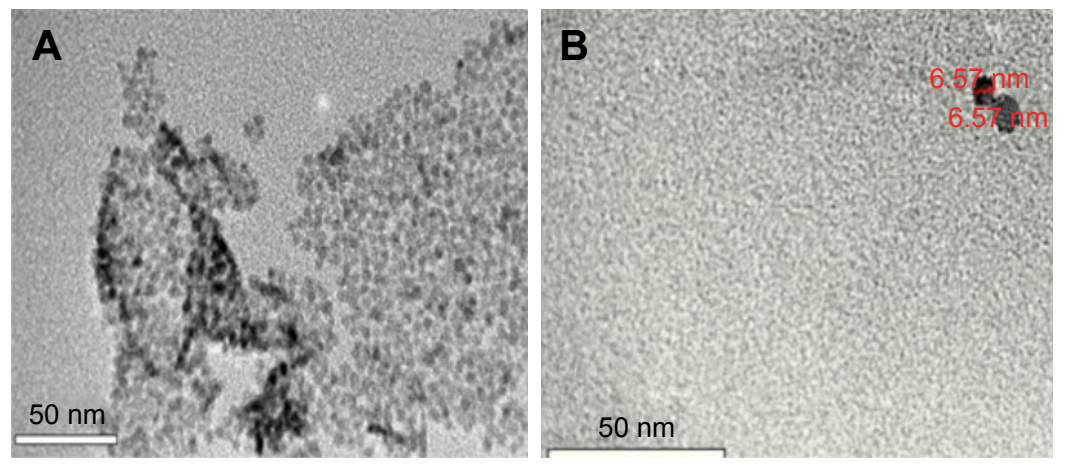

Figure 3 TEM images of (A) clusters of GQDs and (B) size of GQDs (in nm).

Abbreviations: GQDs, graphene quantum dots; TEM, transmission electron microscopy. 


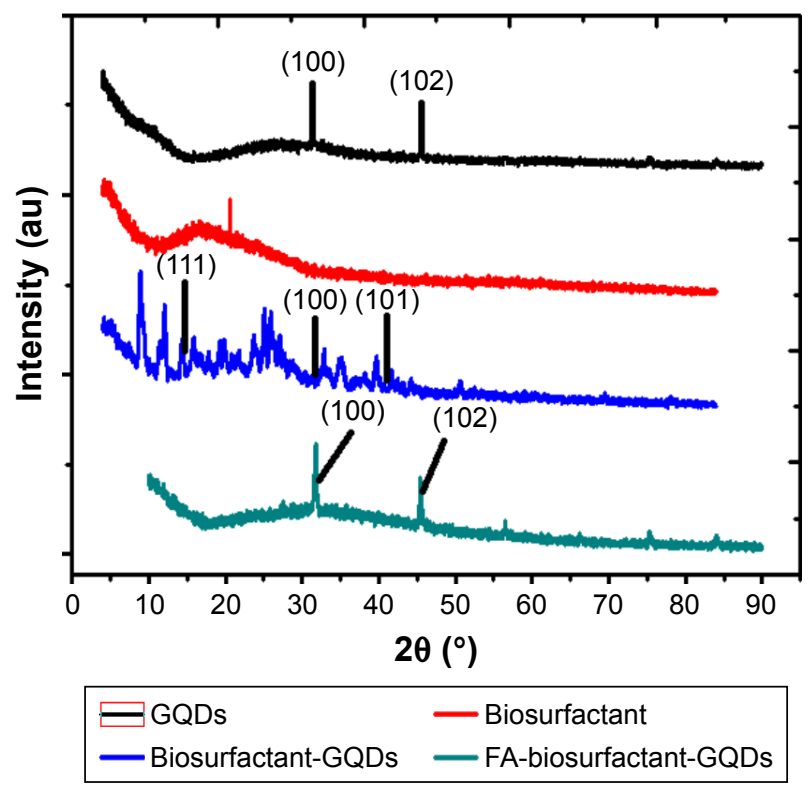

Figure 4 XRD of biosurfactant, GQDs, biosurfactant-GQDs conjugate, and FA-biosurfactant-GQDs conjugate.

Abbreviations: FA, folic acid; GQDs, graphene quantum dots; XRD, X-ray diffraction.

correlated to $(111),{ }^{40}(100),{ }^{39}$ and $(101)^{41}$ miller indices, confirming the crystalline nature as well as hexagonal shape of biosurfactant conjugated GQDs. The slight change in peaks of crystal structure of the GQDs upon conjugation to biosurfactant indicated the modification of the GQDs with biosurfactant. ${ }^{42}$ Moreover, presence of peak at $31.92^{\circ}$ suggested that GQDs have retained their hexagonal shape upon conjugation. Similar consistency was observed by XRD spectra of FA-biosurfactant-GQDs which showed the peaks near $2 \theta$ value of $31.7^{\circ}(100)^{39}$ and $45.5^{\circ}(102){ }^{39}$ The obtained planes of $(100)^{39}$ and $(102)^{39}$ further confirms the hexagonal shape of GQDs even after FA conjugation.

\section{FTIR}

GQDs, biosurfactant conjugated GQDs, and FA-biosurfactant conjugated GQDs were characterized by FTIR spectroscopy and the spectra are shown in Figure 5. The FTIR spectrum of GQDs showed $-\mathrm{C}=\mathrm{O}$ stretch of $-\mathrm{COONa}^{+}$at $1,581 \mathrm{~cm}^{-1}$ (Figure 5) confirming the presence of carbonyl functional group. ${ }^{1}$ Presence of $\mathrm{N}-\mathrm{H}$ stretch of amine group in biosurfactant was observed at $3,375.8 \mathrm{~cm}^{-1}$ in our previous report. ${ }^{30}$ Various other functional groups such as $\mathrm{O}-\mathrm{H}$ group, $\mathrm{C}=\mathrm{O}$ bond stretching, and $\mathrm{C}=\mathrm{C}$ were also observed. ${ }^{30}$ Biosurfactant conjugated GQDs showed appearance of $\mathrm{N}-\mathrm{H}$ stretch of $\mathrm{CONH}$ at $3,362.8 \mathrm{~cm}^{-1}$. Moreover, appearance of $-\mathrm{C}=\mathrm{O}$ stretch of $\mathrm{CONH}$ of biosurfactant conjugated GQDs at

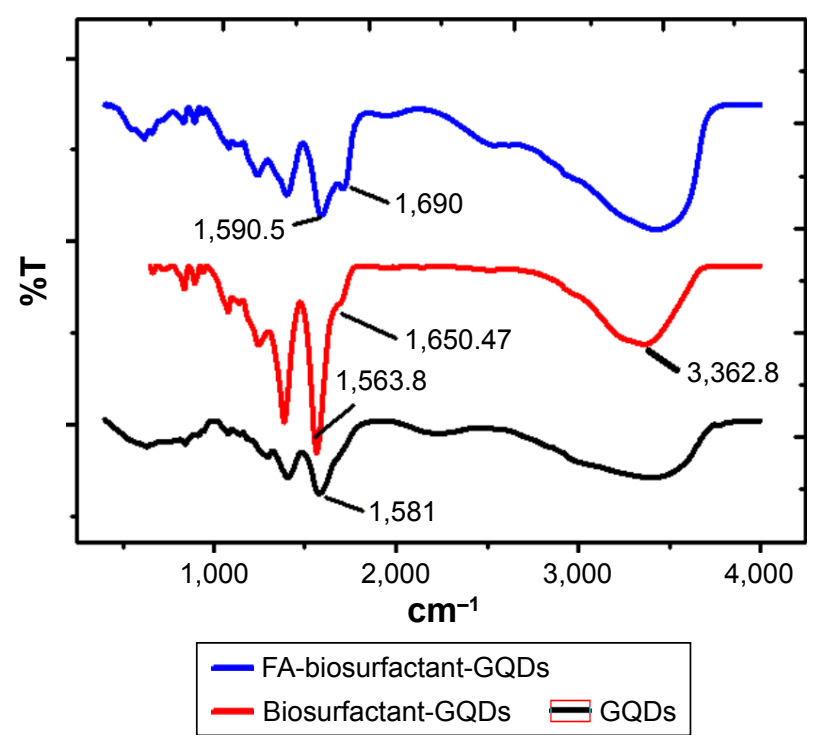

Figure 5 FTIR spectrum of GQDs, biosurfactant-GQDs conjugate, and FAbiosurfactant-GQDs conjugate.

Abbreviations: FA, folic acid; FTIR, Fourier-transform infrared spectroscopy; GQDs, graphene quantum dots.

$1,650.47 \mathrm{~cm}^{-1}$ (amide I) and 1,563.8 $\mathrm{cm}^{-1}$ (amide II) was observed, as shown in Figure $5 .{ }^{42}$ It confirmed the successful bioconjugation of GQDs with biosurfactant. ${ }^{42}$ FTIR spectra of conjugated GQDs showed appearance of $-\mathrm{C}=\mathrm{O}$ stretch of CONH of FA-biosurfactant conjugated GQDs at 1,690 $\mathrm{cm}^{-1}$ (amide I) and 1,590.5 $\mathrm{cm}^{-1}$ (amide II) (Figure 5). ${ }^{43}$ The abovementioned results indicated the presence of FA on the surface of biosurfactant conjugated GQDs.

\section{Zeta potential}

The zeta potential of biosurfactant was $-0.81 \mathrm{mV}$, which indicated that the stability of biosurfactant is less in suspension. ${ }^{44}$ GQDs had a surface charge of $-18 \mathrm{mV}$, which signified that they were highly stable and anionic in nature. Our result was well supported by the reports from other groups. ${ }^{15,35}$ The zeta potential of GQDs-biosurfactant conjugates was measured to be $-13.25 \mathrm{mV}$, which manifested satisfactory level of stability of conjugates in dispersion form.

\section{In vitro cell culture studies}

\section{Cell viability assay}

Figure 6 shows the graphical representation of percent viability of MCF-7 (breast cancer cells) cells after treatment with GQDs and its conjugate with increasing time and dose. It could be seen from graphs (Figure 6A) that GQDs had no significant toxic effects on cells in concentrations ranging from $500 \mu \mathrm{g} / \mathrm{mL}$ to $2,000 \mu \mathrm{g} / \mathrm{mL}$. There was cell viability of 

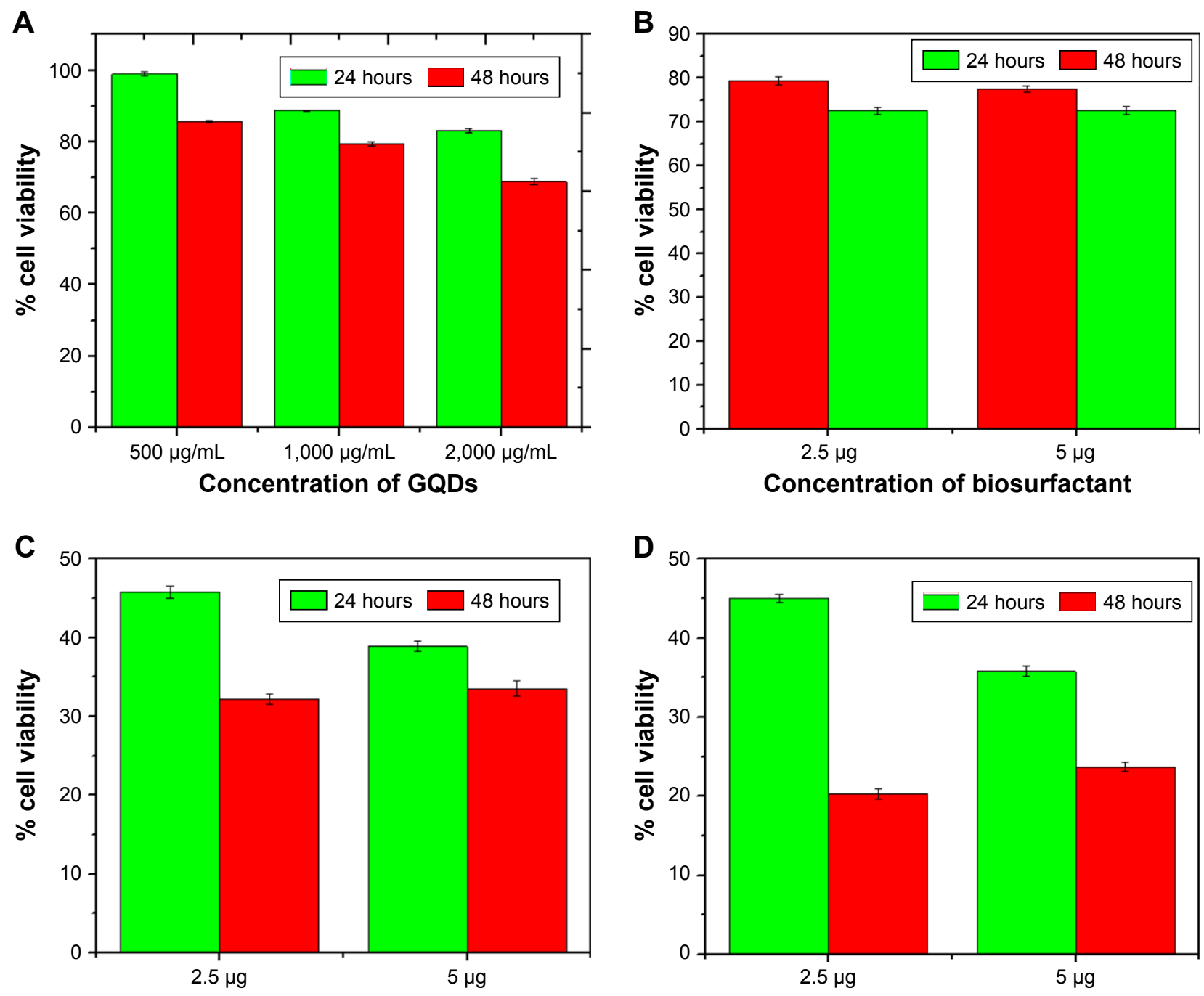

Concentration of GQDbiosurfactant conjugate

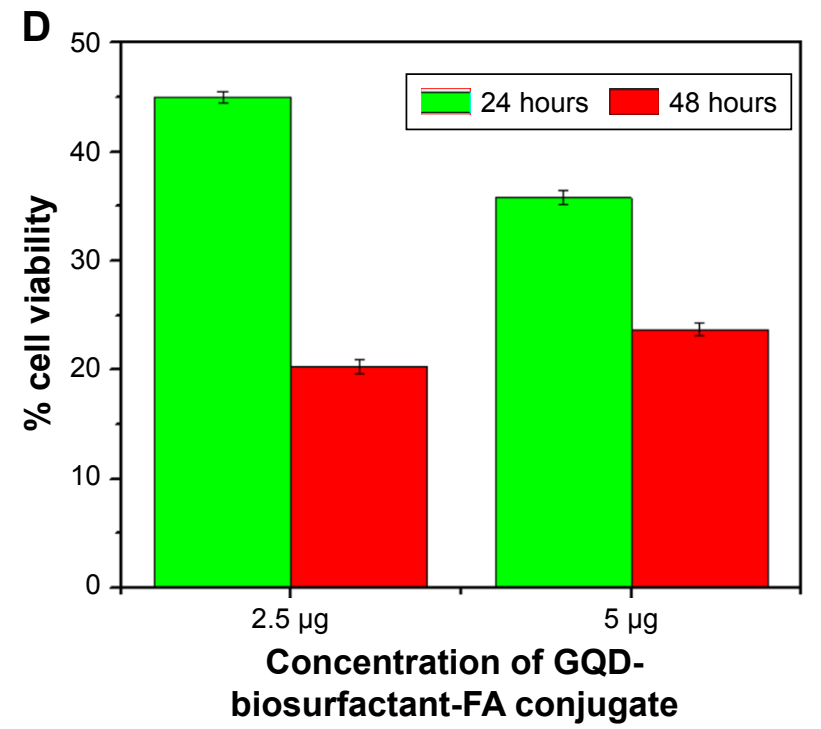

Figure 6 MTT cytotoxicity assay: (A) cytotoxicity of GQDs against MCF-7 cancer cells, (B-D) cytotoxicity of biosurfactant, biosurfactant-GQDs conjugate, and FA-biosurfactant-GQDs conjugate against MCF-7 cancer cells, respectively.

Abbreviations: FA, folic acid; GQDs, graphene quantum dots.

$98 \%$ for $500 \mu \mathrm{g} / \mathrm{mL}$ and decreased to $83 \%$ upto $2,000 \mu \mathrm{g} / \mathrm{mL}$ within 24 hours of GQDs exposure. During 48 hours of exposure of $500 \mu \mathrm{g} / \mathrm{mL}$ and $2,000 \mu \mathrm{g} / \mathrm{mL}$ of GQDs, cell viability decreased to $85 \%$ and $70 \%$, respectively. This result was well corroborated by reports of other groups. ${ }^{11,33}$ However, cells treated with biosurfactant alone (Figure 6B) had shown less cytotoxic effect in comparison to cells treated with biosurfactant conjugated GQDs (Figure 6C). Treatment with biosurfactant conjugated GQDs resulted in 50\% reduction of cell viability within 24 hours when $2.5 \mu \mathrm{g} / \mathrm{mL}$ of biosurfactant was used in bio-conjugation. This viability further decreased by $20 \%$ as time increased to 48 hours. This change could be seen in Figure 6C. It was inferred that biosurfactant conjugated GQDs showed the potential to reduce significant number of viable cancerous cells. Further, conjugation with FA decreased cell viability by more than $60 \%$ within 24 hours of incubation and $75 \%$ after 48 hours of incubation (Figure 6D). This could be due to receptormediated targeting of FA-biosurfactant conjugated GQDs in MCF-7 cells. These observations showed that functionalized GQDs have ample potential to act as therapeutic agent against cancer cells.

\section{Cellular uptake studies using CLSM}

Time-dependent cellular uptake study of GQDs and bioconjugated GQDs was performed for 1, 3, and 6 hours on 

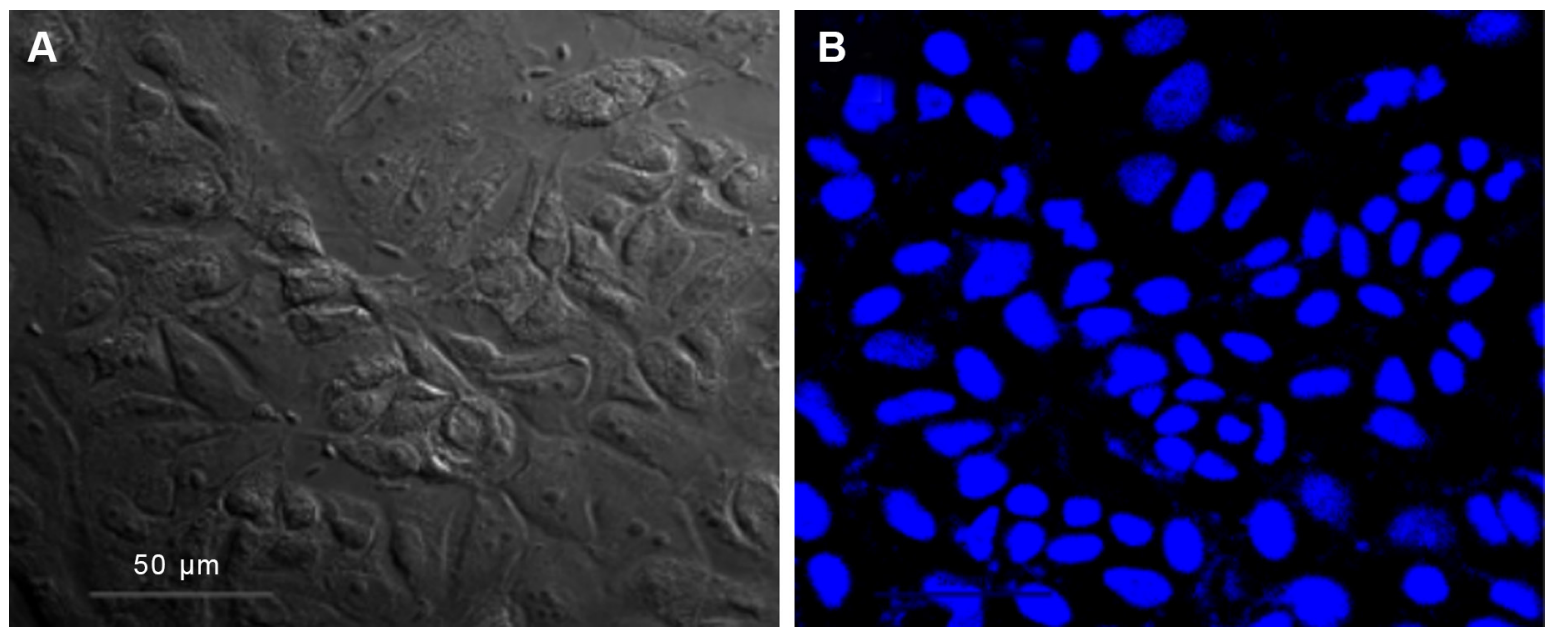

Figure 7 CLSM images of MCF-7 cells (A) under bright field and (B) nucleus stained with DAPI excited by a $405 \mathrm{~nm}$ laser. Abbreviation: CLSM, confocal laser scanning microscopy.

MCF-7 cells. In order to determine and visualize the internalization of plain as well as conjugated QDs, the nuclei of MCF-7 cells were stained with DAPI as could be seen in Figure 7. The cells were observed at $40 \times$ objective using CLSM (Figure 8). Drug internalization was higher in cells treated with FA conjugated GQDs compared to biosurfactant conjugated GQDs. Cellular uptake of FA-biosurfactantGQDs conjugate increased with time period from 1 hour to 6 hours. Better drug internalization with FA conjugated GQDs was due to receptor-mediated endocytosis. ${ }^{32}$

\section{Conclusion}

The present work highlighted the development of a theranostic tool for cancer therapy using GQDs in conjugation with biosurfactant. This tool could be used for diagnosis as well as for therapy of cancer. These bioconjugated GQDs had formed
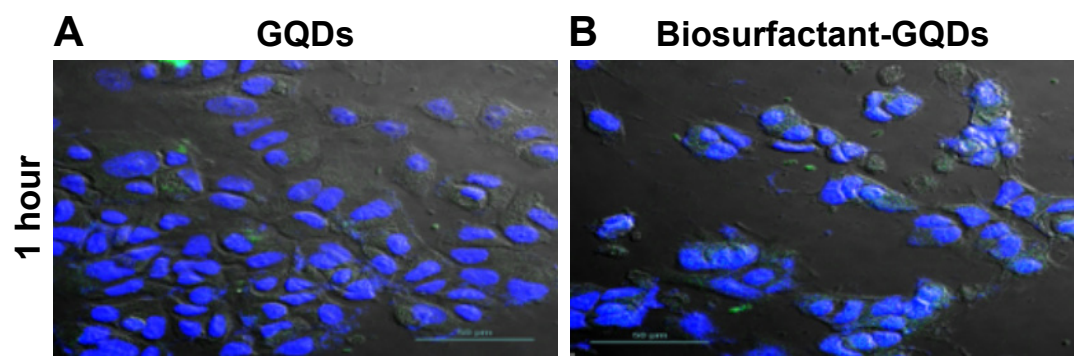

\section{FA-biosurfactant-GQDs}
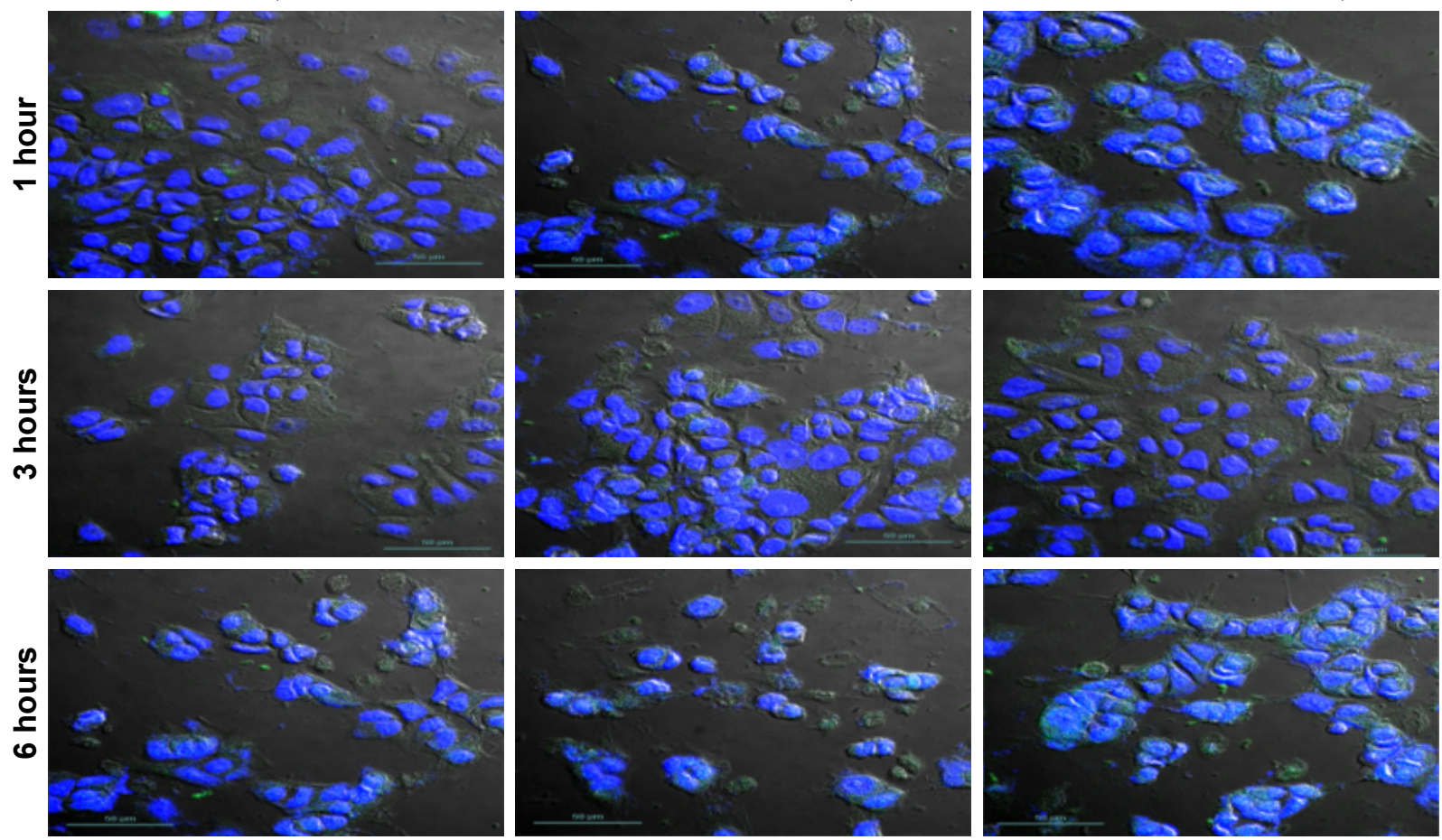

Figure 8 CLSM images of MCF-7 cells treated for I, 3, and 6 hours with (A) GQDs, (B) biosurfactant-GQDs conjugate, and (C) FA-biosurfactant-GQDs conjugate. Scale for all images is $50 \mu \mathrm{m}$.

Abbreviations: CLSM, confocal laser scanning microscopy; FA, folic acid; GQDs, graphene quantum dots. 
homogenous dispersion and had shown stable PL intensity. Folate decoration of bioconjugated GQDs showed enhanced uptake in cancerous cells in comparison to plain GQDs. MTT assay results indicated that conjugation of biosurfactant with GQDs dramatically reduced the viability of cells with increasing time and dose. FA decoration reduced the cell viability further. MTT assay and CLSM results endorsed each other. Moreover, mechanism of action of this bioconjugate at cellular level needs to be unraveled for better understanding of diagnostics and development of cost-effective alternative tools for cancer. Our in vitro results are yet to be extrapolated to in vivo model. In future, this novel nanoconjugate system can open enormous opportunities in biomedical research for using quantum dot-based bioconjugates in cancer diagnosis as well as treatment.

\section{Acknowledgments}

Authors like to thank University Grants Commission (UGC), Basic Scientific Research, Government of India (sanction no. F.30-301/2016 [BSR] dt.16.02.2017) for providing funds to carry out this research endeavor. The authors gratefully acknowledge the Director of the University Institute of Engineering \& Technology, Panjab University, for providing support for this work to be conducted. We acknowledge University Institute of Pharmaceutical Sciences, Central Instrumentation Laboratory/Sophisticated Analytical Instrumentation Facility, Panjab University, and the Institute of Microbial Technology, Chandigarh, for sample analysis and Dr Naveen Gupta for his technical support.

\section{Disclosure}

RPB and GS are supported by the UGC faculty recharge program and Department of Biotechnology (BT/PR27444/ $\mathrm{BRB} / 10 / 1645 / 2018)$. The authors report no other conflicts of interest in this work.

\section{References}

1. Singh G, Zaidi NH, Soni U, et al. Detection of bioconjugated quantum dots passivated with different ligands for bio-applications. J Nanosci Nanotechnol. 2011;11(5):3834-3842.

2. Rosenthal SJ, Chang JC, Kovtun O, McBride JR, Tomlinson ID. Biocompatible quantum dots for biological applications. Chem Biol. 2011;18(1):10-24.

3. Qian ZS, Shan XY, Chai LJ, Ma JJ, Chen JR, Feng H. DNA nanosensor based on biocompatible graphene quantum dots and carbon nanotubes. Biosens Bioelectron. 2014;60:64-70.

4. Zhu JJ, Li JJ, Huang HP, et al. InQuantum Dots for DNA Biosensing. Berlin, Heidelberg: Springer; 2013:9-24.

5. Chen ML, He YJ, Chen XW, Wang JH. Quantum-dot-conjugated graphene as a probe for simultaneous cancer-targeted fluorescent imaging, tracking, and monitoring drug delivery. Bioconjug Chem. 2013;24(3):387-397.
6. Qu D, Zheng M, Li J, Xie Z, Sun Z. Tailoring color emissions from $\mathrm{N}$-doped graphene quantum dots for bioimaging applications. Light Sci Appl. 2015;4(12):e364.

7. Li K, Liu W, Ni Y, et al. Technical synthesis and biomedical applications of graphene quantum dots. J Mater Chem B. 2017;5(25):4811-4826.

8. Kumawat MK, Thakur M, Gurung RB, Srivastava R. Graphene Quantum Dots from Mangifera indica : Application in Near-Infrared Bioimaging and Intracellular Nanothermometry. ACS Sustain Chem Eng. 2017;5(2):1382-1391.

9. Lee J, ChoiY, Kim J, Park E, Song R. Positively charged compact quantum Dot-DNA complexes for detection of nucleic acids. Chemphyschem. 2009;10(5):806-811.

10. Thakur M, Kumawat MK, Srivastava R. Multifunctional graphene quantum dots for combined photothermal and photodynamic therapy coupled with cancer cell tracking applications. RSC Advances. 2017; 7(9):5251-5261.

11. Zhang J, Ma Y-Qiang, Li N, et al. Preparation of graphene quantum dots and their application in cell imaging. J Nanomater. 2016;2016(5):1-9.

12. Sun $\mathrm{H}, \mathrm{Wu} \mathrm{L}, \mathrm{Wei} \mathrm{W}, \mathrm{Qu} X$. Recent advances in graphene quantum dots for sensing. Mater Today. 2013;16(11):433-442.

13. Naik JP, Sutradhar P, Saha M. Molecular scale rapid synthesis of graphene quantum dots (GQDs). J Nanostructure Chem. 2017;7(1):85-89.

14. Roushani M, Mavaei M, Rajabi HR. Graphene quantum dots as novel and green nano-materials for the visible-light-driven photocatalytic degradation of cationic dye. J Mol Catalysis A Chem. 2015;409:102-109.

15. Javanbakht $S$, Namazi H. Solid state photoluminescence thermoplastic starch film containing graphene quantum dots. Carbohydr Polym. 2017; 176:220-226.

16. Ding H, Zhang F, Zhao C, et al. Beyond a Carrier: Graphene Quantum Dots as a Probe for Programmatically Monitoring Anti-Cancer Drug Delivery, Release, and Response. ACS Appl Mater Interfaces. 2017;9(33): 27396-27401.

17. Iannazzo D, Ziccarelli I, Pistone A. Graphene quantum dots: multifunctional nanoplatforms for anticancer therapy. JMater Chem B. 2017;5(32): 6471-6489.

18. Wang $\mathrm{C}, \mathrm{Wu} \mathrm{C}$, Zhou $\mathrm{X}$, et al. Enhancing cell nucleus accumulation and DNA cleavage activity of anti-cancer drug via graphene quantum dots. Sci Rep. 2013;3(1):2852.

19. Habiba K, Bracho-Rincon DP, Gonzalez-Feliciano JA, et al. Synergistic antibacterial activity of PEGylated silver-graphene quantum dots nanocomposites. Appl Mater Today. 2015;1(2):80-87.

20. Fracchia L, Cavallo M, Martinotti MG, Banat IM. Biosurfactants and bioemulsifiers biomedical and related applications-present status and future potentials. In:Ghista GN, editor. Biomedical Science Engineering Technology. Rijeka, Croatia: InTech; 2012:325-370.

21. Karlapudi AP, Venkateswarulu TC, Srirama K, Kota RK, Mikkili I, Kodali VP. Evaluation of anti-cancer, anti-microbial and anti-biofilm potential of biosurfactant extracted from an Acinetobacter M6 strain. J King Saud Univ Sci. Epub 2018 Apr 10.

22. Huang W, Lang Y, Hakeem A, Lei Y, Gan L, Yang X. Surfactin-based nanoparticles loaded with doxorubicin to overcome multidrug resistance in cancers. Int J Nanomed. 2018;13:1723-1736.

23. Dong J, Wang K, Sun L, et al. Application of graphene quantum dots for simultaneous fluorescence imaging and tumor-targeted drug delivery. Sensors Actuators B Chem. 2018;256:616-623.

24. Siwowska K, Schmid R, Cohrs S, Schibli R, Müller C. Folate receptorpositive gynecological cancer cells: In vitro and in vivo characterization. Pharmaceuticals (Basel). 2017;10(3):E72.

25. Schroeder KL, Goreham RV, Nann T. Graphene quantum dots for theranostics and bioimaging. Pharm Res. 2016;33(10):2337-2357.

26. Geszke-Moritz M, Piotrowska H, Murias M, et al. Thioglycerol-capped Mn-doped $\mathrm{ZnS}$ quantum dotbioconjugates as efficient two-photon fluorescent nano-probes for bioimaging. J Mater Chem B. 2013;1(5): 698-706.

27. Leamon CP, Low PS. Delivery of macromolecules into living cells: a method that exploits folate receptor endocytosis. Proc Natl Acad Sci. $1991 ; 88(13): 5572-5576$. 
28. Sui X, Luo C, Wang C, Zhang F, Zhang J, Guo S. Graphene quantum dots enhance anticancer activity of cisplatin via increasing its cellular and nuclear uptake. Nanomedicine. 2016;12(7):1997-2006.

29. Wang X, Sun X, Lao J, et al. Multifunctional graphene quantum dots for simultaneous targeted cellular imaging and drug delivery. Colloids and Surfaces B Biointerfaces. 2014;122:638-644.

30. Garg M, Priyanka, Chatterjee M. Isolation, characterization and antibacterial effect of biosurfactant from Candida parapsilosis. Biotechnol Rep. 2018;18:e0251.

31. He Y, Sun J, Feng D, Chen H, Gao F, Wang L. Graphene quantum dots: Highly active bifunctional nanoprobes for nonenzymatic photoluminescence detection of hydroquinone. Biosens Bioelectron. 2015;74: $418-422$.

32. Singh G, Kumar M, Soni U, et al. Cancer cell targeting using folic acid/anti-HER2 antibody conjugated fluorescent CdSe/CdS/ZnS-MPA and CdTe-MSA quantum dots. J Nanosci Nanotechnol. 2015;15(12): 9382-9395.

33. Nurunnabi M, Khatun Z, Huh KM, et al. In vivo biodistribution and toxicology of carboxylated graphene quantum dots. ACS Nano. 2013; 7(8):6858-6867.

34. Jiang D, Chen Y, Li N, et al. Synthesis of luminescent graphene quantum dots with high quantum yield and their toxicity study. PLoS One. 2015;10(12):e0144906.

35. Wu X, Tian F, Wang W, Chen J, Wu M, Zhao JX. Fabrication of highly fluorescent graphene quantum dots using L-glutamic acid for in vitro/ in vivo imaging and sensing. J Mater Chem C Mater. 2013;1(31): 4676-4684.

36. Magthalin CJ, Varadharajan A, Swarnalatha S, Sekaran G. Utilization of chicken tallow for the production of cationic biosurfactant and thereof for decontamination of $\mathrm{Cr}$ (III) containing soil. Procedia Environ Sci. 2016;35:895-913.
37. Zheng XT, Ananthanarayanan A, Luo KQ, Chen P. Glowing graphene quantum dots and carbon dots: properties, syntheses, and biological applications. Small. 2015;11(14):1620-1636.

38. Jia F, Lv S, Xu S. Bio-conjugation of graphene quantum dots for targeting imaging. RSC Adv. 2017;7(84):53532-53536.

39. Maiti S, Kundu S, Roy CN, Das TK, Saha A. Synthesis of excitation independent highly luminescent graphene quantum dots through perchloric acid oxidation. Langmuir. 2017;33(51):14634-14642.

40. Sherwood D, Emmanuel B Inventors. Council of Scientific, Industrial Research (CSIR), assignee. Method for computing crystal shapes from X-ray diffraction data (XRD) of a substance. United States Patent US. 2010;7(739):075.

41. Sangam S, Gupta A, Shakeel A, et al. Sustainable synthesis of single crystalline sulphur-doped graphene quantum dots for bioimaging and beyond. Green Chem. 2018;20(18):4245-4259.

42. Nwahara N, Nkhahle R, Ngoy BP, Mack J, Nyokong T. Synthesis and photophysical properties of BODIPY-decorated graphene quantum dot-phthalocyanine conjugates. New J Chem. 2018;42(8):6051-6061.

43. Balan SS, Kumar CG, Jayalakshmi S. Aneurinifactin, a new lipopeptide biosurfactant produced by a marine Aneurinibacillus aneurinilyticus SBP-11 isolated from Gulf of Mannar: purification, characterization and its biological evaluation. Microbiol Res. 2017;194:1-9.

44. Bhattacharjee S. DLS and zeta potential - What they are and what they are not? J Control Release. 2016;235:337-351.
International Journal of Nanomedicine

\section{Publish your work in this journal}

The International Journal of Nanomedicine is an international, peerreviewed journal focusing on the application of nanotechnology in diagnostics, therapeutics, and drug delivery systems throughout the biomedical field. This journal is indexed on PubMed Central, MedLine, CAS, SciSearch $\AA$, Current Contents ${ }^{\circledR} /$ Clinical Medicine,

\section{Dovepress}

Journal Citation Reports/Science Edition, EMBase, Scopus and the Elsevier Bibliographic databases. The manuscript management system is completely online and includes a very quick and fair peer-review system, which is all easy to use. Visit http://www.dovepress.com/ testimonials.php to read real quotes from published authors. 